\title{
Adsorption of benzoic acid by CTAB exchanged montmorillonite
}

\author{
Liang-Guo Yan ${ }^{\mathrm{a}}$, Jin Wang ${ }^{\mathrm{b}}$, Hai-Qin Yu ${ }^{\mathrm{b}}$, Qin Wei ${ }^{\mathrm{b}, *}$, Bin Du ${ }^{\mathrm{b}}$, Xiao-Quan Shan ${ }^{\mathrm{a}}$ \\ ${ }^{a}$ State Key Laboratory of Environmental Chemistry and Ecotoxicology, Research Center for Eco-Environmental Sciences, \\ Chinese Academy of Sciences, Beijing 100085, China \\ b School of Chemistry and Chemical Engineering, Jinan University, Jinan 250022, China
}

Received 6 June 2006; received in revised form 25 December 2006; accepted 30 December 2006

Available online 17 January 2007

\begin{abstract}
This paper reports the adsorption of benzoic acid from water on cetyl trimethylammonium exchanged montmorillonite (CTAB-montmorillonite). Important factors are the adsorbent concentration, ionic strength, equilibrium time and $\mathrm{pH}$. The largest adsorption is at $\mathrm{pH}$ 9. The adsorption kinetics data fitted the pseudo-second-order equation. The adsorption isotherms at different $\mathrm{pH}$ were linear indicating a partition mechanism. Up to about $61 \%$ of the dissolved benzoic acid was adsorbed by CTAB-montmorillonite. These results indicate that CTAB-montmorillonite is a potential adsorbent for benzoic acid.
\end{abstract}

(c) 2007 Elsevier B.V. All rights reserved.

Keywords: Organo-montmorillonite; Adsorption; Benzoic acid; Adsorption kinetics

\section{Introduction}

The current rapid growth of industry in China is accompanied by an increase in the amount of wastewater discharged, as is the case in many regions with rapid industrial growth. These wastewaters contain many toxic organic and inorganic materials, such as aromatic compounds, heavy metals and dyes. Many of them have been classified as hazardous pollutants because of their potential toxicity to human health. Benzoic acid and its sodium benzoate are widely used as preservatives in beverages, fruit products, chemically leavened baked goods, and condiments. Also, chemical intermediates are of great relevance in the chemical industry (World

\footnotetext{
* Corresponding author.

E-mail addresses: yanliangguo@163.com (L.-G. Yan), sdjndxwq@263.net, sdjndxwq@163.com(Q. Wei).
}

Health Organization, 2000). The wastewater discharged from processes of manufacture and application can pollute water, soil and atmosphere. The concentration of benzoic acid was found to range from 10 to $27500 \mu \mathrm{g} / \mathrm{L}$ in the groundwater of Florida (Goerlitz et al., 1985).

In order to meet the increasing stringent environmental regulations, many technologies such as chemical oxidation, biological degradation, solvent extraction, and adsorption were developed to remove the toxic organic compounds from industrial wastewaters. Adsorption on carbon is most popular. Because of the relative high costs of activated carbon, attempts have been made to use clays and clay minerals and some oxides as adsorbents, such as kaolins, bentonites and iron oxides (Krishna et al., 2001; Rosen and Li, 2001; Angove et al., 2002; Espantaleon et al., 2003; Ferreiro and Bussetti, 2003; Hizal and Apak, 2006). The application of clays, especially bentonites has 
attracted more and more interest because of their high cation exchange capacity, surface area and wide availability. The adsorption of neutral organic contaminants can be greatly improved by replacing the inorganic interlayer cations by organic cations such as quaternary ammonium cations (Boyd et al., 1988). At present, organo-montmorillonite can act as adsorbent for a great variety of organic pollutants, such as phenols (Lawrence et al., 1998; Jiang et al., 2002; Juang et al., 2002; Barhoumi et al., 2003), trichlorobenzene and aniline (Dentel et al., 1998).

Benzoic acid is a weakly acid. Several studies have been reported in the literature on the adsorption by various materials, such as activated carbon (Chern and Chien, 2003; Ayranci et al., 2005), metal(hydr)oxides (Horányi, 2002), modified loess soil (Zhou et al., 2003) and mesoporous materials (Huang et al., 2004; Tozuka et al., 2005). However, very little information is available regarding the adsorption of benzoic acid by organomontmorillonite (Yildiz et al., 2005). We found that adsorptive capacity of CTAB-montmorillonite for benzoic acid is much better than that of natural montmorillonite.

\section{Materials and methods}

\subsection{Materials}

The bentonite used for this study was natural montmorillonite, purchased from BeijingYoulichuangjia Science and Technology Developing Company and mined in Yixian, Hebei province, China. According to the supplier, the sample contained $98 \%$ montmorillontte, $0.5 \%$ kaolinite and $1.0 \%$ quartz. The chemical composition was $\mathrm{SiO}_{2}, 50.90 \%, \mathrm{Al}_{2} \mathrm{O}_{3}$, $18.36 \%, \mathrm{Fe}_{2} \mathrm{O}_{3}, 1.03 \%, \mathrm{CaO}, 3.97 \%, \mathrm{MgO}, 4.14 \%, \mathrm{TiO}_{2}$, $0.02 \%, \mathrm{~K}_{2} \mathrm{O}, 0.72 \%, \mathrm{Na}_{2} \mathrm{O}, 1.18 \%, \mathrm{P}_{2} \mathrm{O}_{5}, 2.15 \%$.

Benzoic acid, CTAB and sodium, potassium and calcium chloride were of analytical grade.

\subsection{Preparation of CTAB-montmorillonite}

The bentonite was dispersed in $500 \mathrm{~mL} 0.5 \mathrm{~mol} / \mathrm{L} \mathrm{NaCl}$ solution, shaken for $24 \mathrm{~h}$ before the clear supernatant was discarded. The bentonite was again dispersed in $500 \mathrm{~mL}$ $0.5 \mathrm{~mol} / \mathrm{L} \mathrm{NaCl}$ solution. The remaining solid was washed with deionized water several times until absence of chloride ions (tested with $\mathrm{AgNO}_{3}$ solution). The product was dried at $80{ }^{\circ} \mathrm{C}$ and gently ground in an agate mortar. The cation exchange capacity (CEC) of this $\mathrm{Na}^{+}$-exchanged montmorillonite $(1.0 \mathrm{mmol} / \mathrm{g})$ was determined by reacting with $\mathrm{BaCl}_{2-}$ $\mathrm{H}_{2} \mathrm{SO}_{4}$ (Leij and Dane, 1989). $25 \mathrm{~g}$ of $\mathrm{Na}^{+}$-exchanged montmorillonite were reacted with $\mathrm{CTAB}$ solution equivalent to the CEC, and then shaken for $24 \mathrm{~h}$, the clear supernatant was discarded. The organo-modified montmorillonite was washed several times with deionized water, until bromide ions were absent in the supernatant. The organo-montmorillonite was dried at $80^{\circ} \mathrm{C}$, then crushed and sieved to a size range of $0.3 \sim$ $0.5 \mathrm{~mm}$.

\subsection{Characterization}

The X-ray diffraction (XRD) patterns were measured on a Rigaku D/MAX 2200 (Tokyo, Japan) instrument with $\mathrm{CuK \alpha}$ radiation $(\lambda=1.5405 \AA)$. Surface area measurement was performed on NOVA 2000e surface area and pore size analyzer (Quantachrome, American). The samples were outgassed overnight $(20 \mathrm{~h})$ under nitrogen prior to the adsorption measurement. The specific surface area was calculated on the basis of the BET equation.

\subsection{Adsorption experiments}

The adsorption experiments were performed by a batch technique at room temperature. Briefly, $0.2 \mathrm{~g}$ of CTABmontmorillonite were placed in a series of glass centrifuge tubes, and supplemented with $10 \mathrm{~mL}$ different concentrations of benzoic acid solution and $0.1 \mathrm{~mL}$ of $0.4 \mathrm{~mol} / \mathrm{L} \mathrm{CaCl}_{2}$. The $\mathrm{pH}$ of the suspensions was adjusted to 3.0, 7.0 and 9.0 with 1: $1 \mathrm{HCl}$ or $\mathrm{NaOH}$. The flasks were shaken for $24 \mathrm{~h}$. After equilibrium, the suspensions were centrifuged at $4000 \mathrm{r} / \mathrm{min}$ for $30 \mathrm{~min}$ and the supernatants were analyzed by a UV spectrophotometer. The adsorbed amounts of benzoic acid were calculated by the difference between the initial and final concentration in the equilibrium solution.

\subsection{Determination of benzoic acid}

The concentration of benzoic acid was determined in the UV-2450 spectrometer (Shimadzu, Japan) at $223 \mathrm{~nm}$ between 0 and $0.1 \mathrm{mmol} / \mathrm{L}$. The linear regression was $A=7.82 c-0.0283$ with a regression coefficient of 0.998 .

\section{Results and discussion}

\subsection{Characterization of montmorillonite}

Data of natural montmorillonite, $\mathrm{Na}^{+}$-montmorillonite and CTAB-montmorillonite were listed in Table 1. It is interesting to note that the specific BET surface area of the organo-montmorillonite was only $4 \mathrm{~m}^{2} / \mathrm{g}$ because the organic ions had been intercalated into the interlayer spaces.

\subsection{Preliminary determinations}

As shown in Fig. 1, the proportion of benzoic acid adsorbed increased slightly with the mass of the organomontmorillonite and $0.02 \mathrm{~g} / \mathrm{mL}$ CTAB-montmorillonite was used in the following experiments. We observed an influence of the added salts on the adsorption (Fig. 2) 
Table 1

Summary of XRD analysis results and BET surface area of natural montmorillonite, $\mathrm{Na}^{+}$-montmorillonite and CTAB-montmorillonite

\begin{tabular}{llll}
\hline Sorbent & BET surface area $\left(\mathrm{m}^{2} / \mathrm{g}\right)$ & $2 \theta\left({ }^{\circ}\right)$ & $d_{001}(\AA)$ \\
\hline Natural montmorillonite & 10.15 & 5.722 & 15.43 \\
$\mathrm{Na}^{+}$-montmorillonite & 10.52 & 7.024 & 12.57 \\
CTAB-montmorillonite & 4.050 & 4.661 & 18.94 \\
\hline
\end{tabular}

which increased in the order: $\mathrm{NaCl}<\mathrm{KCl}<\mathrm{CaCl}_{2}$. Therefore, $\mathrm{CaCl}_{2}$ was chosen as the background electrolyte and at an ionic strength of $0.004 \mathrm{~mol} / \mathrm{L}$.

\subsection{Adsorption kinetics}

The relationship between contact time and benzoic acid uptake by CTAB-montmorillonite is presented in Fig. 3. The equilibrium time required for the adsorption of benzoic acid is almost $12 \mathrm{~h}$. To ensure equilibrium, all the experiments were left for $24 \mathrm{~h}$.

The adsorption of benzoic acid onto CTAB-montmorillonite fits the pseudo-second-order equation

$\frac{\mathrm{d} q_{t}}{\mathrm{~d} t}=k\left(q_{e}-q_{t}\right)^{2}$

Integrating the equation for the boundary conditions $t=0$ to $t=t$ and $q_{t}=0$ to $q_{t}=q_{t}$, and rearrangement into the linear form gives:

$\frac{t}{q_{t}}=\frac{1}{k q_{e}^{2}}+\frac{1}{q_{e}} t$

where $q_{e}(\mathrm{mmol} / \mathrm{g})$ and $q_{t}(\mathrm{mmol} / \mathrm{g})$ are the amount of solute adsorbed by adsorbent at equilibrium and at time $t(\mathrm{~h}), k(\mathrm{~g} / \mathrm{mmol} / \mathrm{h})$ is the rate constant. The plot of $t / q_{\mathrm{t}}$ against $t$ should give a linear relationship with a slope of

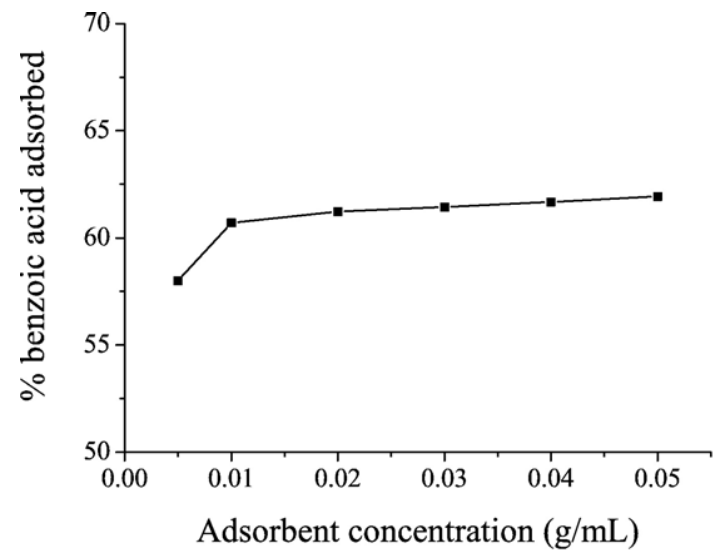

Fig. 1. Effect of CTAB-montmorillonite concentration on the adsorption of benzoic acid at an initial concentration of $10 \mathrm{mmol} / \mathrm{L}$ in deionized water.

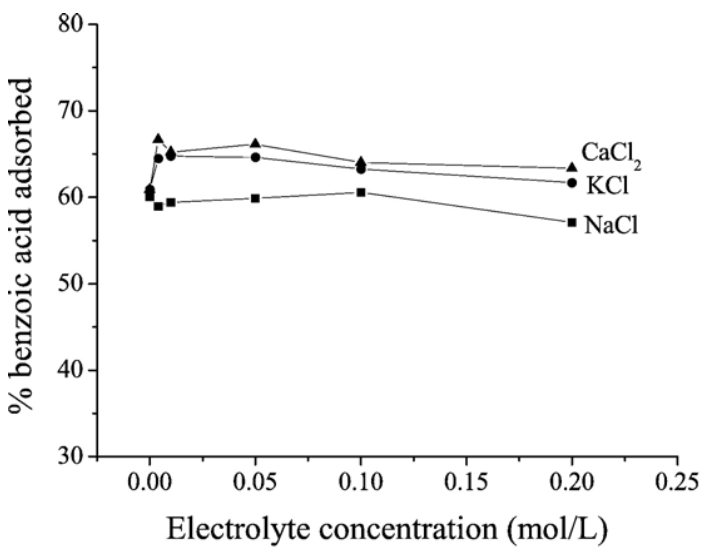

Fig. 2. Effect of $\mathrm{NaCl}, \mathrm{KCl}$ and $\mathrm{CaCl}_{2}$ concentrations on the adsorption of benzoic acid on CTAB-montmorillonite. Initial concentration of benzoic acid was $10 \mathrm{mmol} / \mathrm{L}$ and the amounts of adsorbent were $0.02 \mathrm{~g} / \mathrm{mL}$.

$1 / q_{\mathrm{e}}$ and an intercept of $1 / k q_{e}^{2}$. The measured kinetic data fitted this model (Fig. 4) with a correlation coefficient of 0.991 . The rate constants $k$ and adsorption capacity at saturation $q_{e}$ were calculated from the values of the slopes and the intercepts. They were $0.4497 \mathrm{~g} / \mathrm{mmol} / \mathrm{h}$ and $0.3904 \mathrm{mmol} / \mathrm{g}$. Similar second order kinetics has been reported for phenol adsorption by organo-clays by other authors (Juang et al., 2002; Y1lmaz and Yapar, 2004).

\subsection{Adsorption isotherms}

The adsorption isotherms of benzoic acid onto CTAB-montmorillonite are linear (Fig. 5):

$q_{e}=K_{p} C_{e}$

where $q_{e}(\mathrm{mmol} / \mathrm{g})$ is the amount of adsorption and $C_{e}$ $(\mathrm{mmol} / \mathrm{L})$ is the equilibrium concentration of the

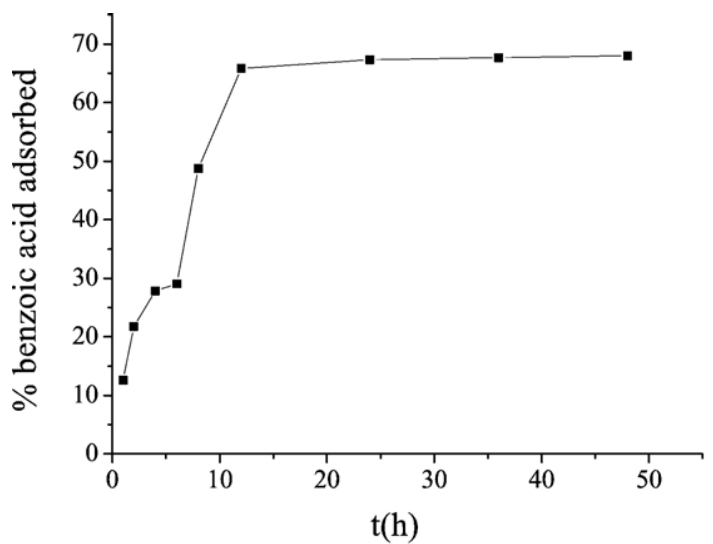

Fig. 3. Adsorption kinetics of benzoic acid adsorption on CTABmontmorillonite at an initial concentration of $10 \mathrm{mmol} / \mathrm{L}$. The amounts of adsorbent were $0.02 \mathrm{~g} / \mathrm{mL}$ and the background electrolyte was $0.004 \mathrm{~mol} / \mathrm{L} \mathrm{CaCl}_{2}$. 


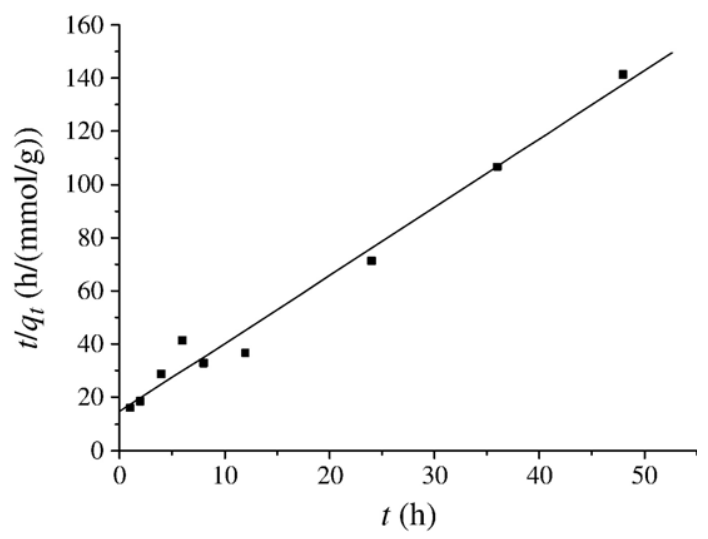

Fig. 4. Pseudo-second-order kinetics for the adsorption of benzoic acid on CTAB-montmorillonite.

adsorbate. The $K_{p}(\mathrm{~g} / \mathrm{L})$ represents the ratio of the amount of a material adsorbed to the amount in solution. Linear regressions were thus performed for each isotherm and the results were given in Table 2.

The isotherms are linear over a wide range of equilibrium concentrations, up to about $61 \%$ of the solubility of benzoic acid in water. The linearity of the isotherms indicates a partition mechanism in the adsorption of benzoic acid by CTAB-montmorillonite, as reported (Boyd et al., 1988; Lee et al., 1989; Smith et al., 1990) for the adsorption of other hydrophobic organic compounds by organo-clays.

\subsection{Effect of $p H$}

According to Fig. 5 and Table 2, the adsorption of benzoic acid onto CTAB-montmorillonite increases as the $\mathrm{pH}$ value increases from 3.0 to 9.0. Generally, benzoic acid

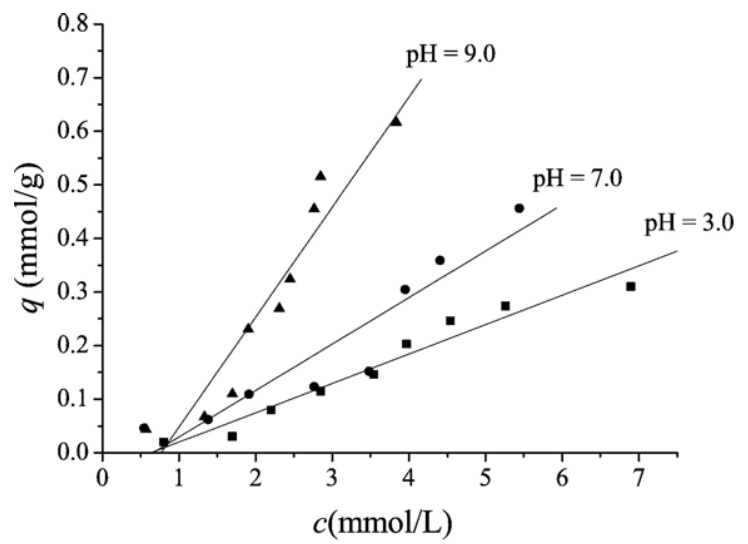

Fig. 5. Adsorption isotherms of benzoic acid at different $\mathrm{pH}$ values. The amounts of adsorbent were $0.02 \mathrm{~g} / \mathrm{mL}$ and the background electrolyte was $0.004 \mathrm{~mol} / \mathrm{L} \mathrm{CaCl}_{2}$.
Table 2

Linear regression parameters of benzoic acid adsorption on CTABmontmorillonite

\begin{tabular}{llll}
\hline $\mathrm{pH}$ & $K_{p}$ & Intercept & $R^{2}$ \\
\hline 3 & 0.0548 & -0.0349 & 0.9548 \\
7 & 0.0867 & -0.0574 & 0.8850 \\
9 & 0.2051 & -0.1567 & 0.9140 \\
\hline
\end{tabular}

is present in neutral form when $\mathrm{pH}$ is less than 2 units of its $\mathrm{pKa} 4.21$. At $\mathrm{pKa}, 50 \%$ of the benzoic acid is present as anion, and at $\mathrm{pH}>4.21$, anions are predominated. Benzoic acid and the conjugated base are of different hydrophobicity. Hence the amount of benzoic acid partitioned to CTAB-montmorillonite should be $\mathrm{pH}$ dependent.

\section{Conclusion}

Optimal conditions for the adsorption of benzoic acid on CTAB-montmorillonite were $0.02 \mathrm{~g} / \mathrm{mL}$ adsorbent, $\mathrm{CaCl}_{2}$ as electrolyte at an ionic strength of $0.004 \mathrm{~mol} / \mathrm{L}$ and $\mathrm{pH}$ of 9.0. The observed adsorption kinetics fitted the pseudo-second-order kinetics equation. The adsorption isotherms were linear which indicated a partition mechanism. Amounts up to about $61 \%$ of the maximum solubility of benzoic acid in water were adsorbed on CTAB-montmorillonite. Thus, CTAB-montmorillonite might be used as potential adsorbent for removing benzoic acid from water.

\section{Acknowledgements}

This study was supported by Natural Science Foundation of China (Grant No.20577016), the Natural Science Foundation (Y2004B11), the Science and Technology Program of Shandong Province (03C05) and the Jinan University Doctoral Foundation (B0405), and all the authors express their deep thanks.

\section{References}

Angove, M.J., Fernandes, M.B., Ikhsan, J., 2002. The sorption of anthracene onto goethite and kaolinite in the presence of some benzene carboxylic acids. J. Colloid Interface Sci. 247, 282-289.

Ayranci, E., Hoda, N., Bayram, E., 2005. Adsorption of benzoic acid onto high specific area activated carbon cloth. J. Colloid Interface Sci. 284, 83-88.

Barhoumi, M., Beurroies, I., Denoyel, R., Sa1d, H., Hanna, K., 2003. Coadsorption of phenol and nonionic surfactants onto clays. Colloids Surf., A Physicochem. Eng. Asp. 223, 63-72.

Boyd, S.A., Lee, J.-F., Mortland, M.M., 1988. Attenuating organic contaminant mobility by soil modification. Nature 333, 345-347.

Chern, J.-M., Chien, Y.-W., 2003. Competitive adsorption of benzoic acid and $p$-nitrophenol onto activated carbon: isotherm and breakthrough curves. Water Res. 37, 2347-2356. 
Dentel, S.K., Jamrah, A.I., Sparks, D.L., 1998. Sorption and cosorption of 1,2,4-trichlorobenzene and tannic acid by organoclays. Water Res. 32, 3689-3697.

Espantaleon, A.G., Nieto, J.A., Fernandez, M., Marsal, A., 2003. Use of activated clays in the removal of dyes and surfactants from tannery waste waters. Appl. Clay Sci. 24, 105-110.

Ferreiro, E.A., Bussetti, S.G., 2003. Partial specific adsorption of organic molecules in binary mixtures of adsorbents: 2,2'bipyridine on kaolinite and hematite and 1,10-phenanthroline on montmorillonite and hydroxyl-Al montmorillonite. J. Colloid Interface Sci. 262, 32-37.

Goerlitz, D.F., Troutman, D.E., Godsy, E.M., Franks, B.J., 1985. Migration of wood-preserving chemicals in contaminated groundwater in a sand aquifer at Pensacola, Florida. Environ. Sci. Technol. 15, 955-961.

Hizal, J., Apak, R., 2006. Modeling of copper(II) and lead(II) adsorption on kaolinite-based clay minerals individually and in the presence of humic acid. J. Colloid Interface Sci. 295, 1-13.

Horányi, G., 2002. Specific adsorption of simple organic acids on metal(hydr)oxides: a radiotracer approach. J. Colloid Interface Sci. 254, 214-221.

Huang, L., Xiao, G., Ni, Y., 2004. Cation MCM-41: synthesis, characterization and sorption behavior towards aromatic compounds. Colloids Surf., A Physicochem. Eng. Asp. 247, 129-136.

Jiang, J.Q., Cooper, C., Quki, S., 2002. Comparison of modified montmorillonite adsorbents part I: preparation, characterization and phenol adsorption. Chemosphere 47, 711-716.

Juang, R.-S., Lin, S.-H., Tsao, K.-H., 2002. Mechanism of sorption of phenols from aqueous solutions onto surfactant-modified montmorillonite. J. Colloid Interface Sci. 254, 234-241.

Krishna, B.S., Murty, D.S.R., Jai, P.B.S., 2001. Surfactant-modified clay as adsorbent for chromate. Appl. Clay Sci. 20, 65-71.

Lawrence, M.A.M., Kukkadapu, R.K., Boyd, S.A., 1998. Adsorption of phenol and chlorinated phenols from aqueous solution by tetramethylammonium- and tetramethylphosponium-exchanged montmorillonite. Appl. Clay Sci. 13, 13-20.

Lee, J.F., Mortland, M.M., Boyd, S.A., Chiou, C.T., 1989. Shapeselective adsorption of aromatic molecules from water by tetramethylammonium-smectite. J. Chem. Soc., Faraday Trans. I 85, 2953-2962.

Leij, F.J., Dane, J.H., 1989. Evaluation of methods to determine CEC and exchange isotherms for modeling transport. Dept. of Agronomy and Soils Dept. Series No. 134. Alabama Agricultural Experiment Station, Auburn University, pp. 10-11.

Rosen, M.J., Li, F., 2001. The adsorption of gemini and conventional surfactants onto some soil solids and the removal of 2-naphthol by the soil surfaces. J. Colloid Interface Sci. 234, 418-424.

Smith, J.A., Jaffe, P.R., Chiou, C.T., 1990. Effect of ten quaternary ammonium cations on tetrachloromethane sorption to clay form water. Environ. Sci. Technol. 24, 1167-1172.

Tozuka, Y., Sasaoka, S., Nagae, A., Moribe, K., Oguchi, T., Yamamoto, K., 2005. Rapid adsorption and entrapment of benzoic acid molecules onto mesoporous silica (FSM-16). J. Colloid Interface Sci. 291, 471-476.

World Health Organization, 2000. Concise International Chemical Assessment Document 26, Benzoic Acid and Sodium Benzoate. Geneva, Switzerland.

Yıldız, N., Gönülșen, R., Koyuncu, H., Çalımlı, A., 2005. Adsorption of benzoic acid and hydroquinone by organically modified bentonites. Colloids Surf., A Physicochem. Eng. Asp. 260, 87-94.

Y1lmaz, N., Yapar, S., 2004. Adsorption properties of tetradecyl- and hexadecyl trimethylammonium bentonites. Appl. Clay Sci. 27, 223-228.

Zhou, W., Zhu, K., Zhan, H., Jiang, M., Chen, H., 2003. Sorption behaviors of aromatic anions loess soil modified with cationic surfactant. J. Hazard. Mat. B100, 209-218. 